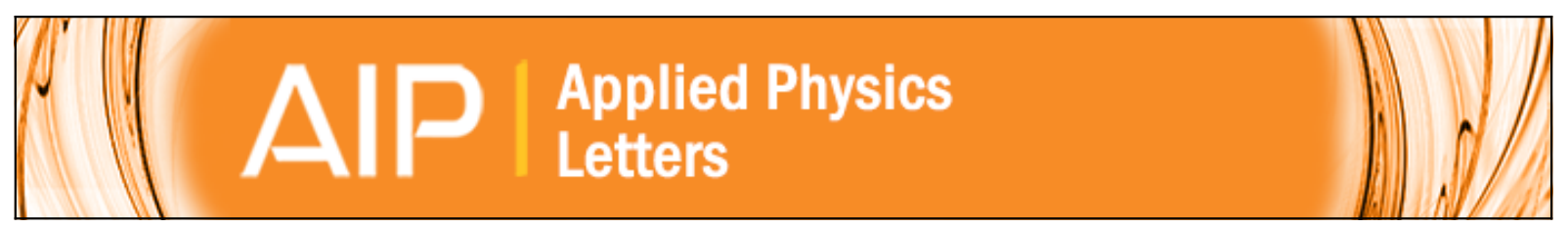

\title{
Thermoelectric performance of co-doped SnTe with resonant levels
}

Min Zhou, Zachary M. Gibbs, Heng Wang, Yemao Han, Laifeng Li, and G. Jeffrey Snyder

Citation: Applied Physics Letters 109, 042102 (2016); doi: 10.1063/1.4959845

View online: http://dx.doi.org/10.1063/1.4959845

View Table of Contents: http://scitation.aip.org/content/aip/journal/apl/109/4?ver=pdfcov

Published by the AIP Publishing

\section{Articles you may be interested in}

Effect of potassium doping on electronic structure and thermoelectric properties of topological crystalline insulator

Appl. Phys. Lett. 108, 193901 (2016); 10.1063/1.4948969

Optimization of thermoelectric properties in n-type SnSe doped with $\mathrm{BiCl} 3$

Appl. Phys. Lett. 108, 083902 (2016); 10.1063/1.4942890

Quasiparticle band structures and thermoelectric transport properties of p-type SnSe

J. Appl. Phys. 117, 065103 (2015); 10.1063/1.4907805

Influence of substituting $\mathrm{Sn}$ for $\mathrm{Sb}$ on the thermoelectric transport properties of CoSb3-based skutterudites

J. Appl. Phys. 115, 103704 (2014); 10.1063/1.4867609

Effect of $\mathrm{Ag}$ or $\mathrm{Sb}$ addition on the thermoelectric properties of $\mathrm{PbTe}$

J. Appl. Phys. 108, 113709 (2010); 10.1063/1.3517088

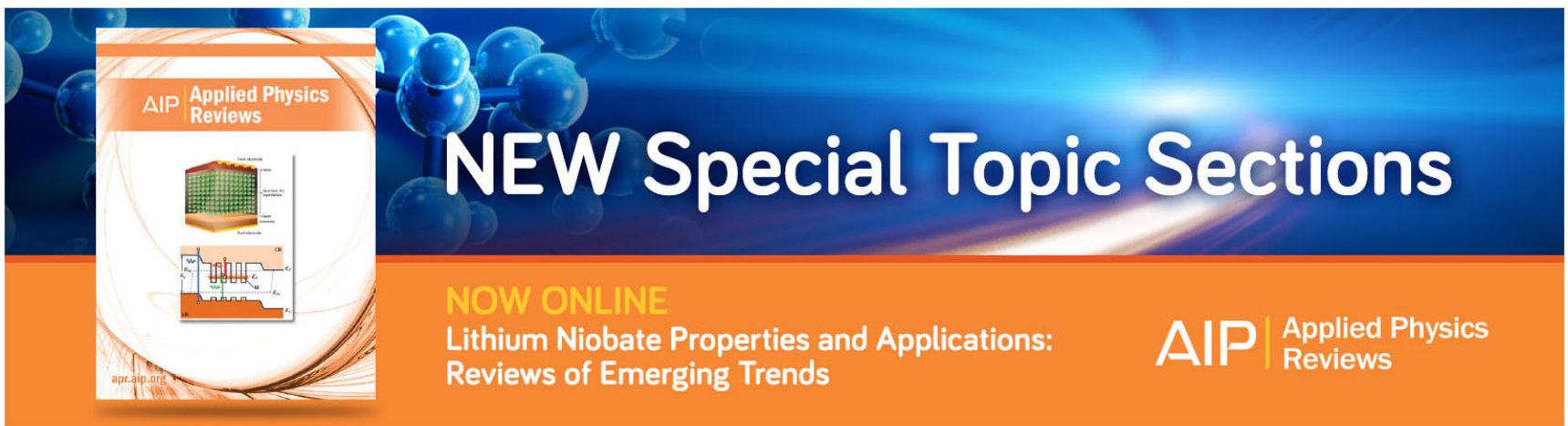




\title{
Thermoelectric performance of co-doped SnTe with resonant levels
}

\author{
Min Zhou, ${ }^{1}$ Zachary M. Gibbs, ${ }^{2}$ Heng Wang, ${ }^{3, a)}$ Yemao Han, ${ }^{1}$ Laifeng Li, ${ }^{1, a)}$ \\ and G. Jeffrey Snyder ${ }^{3,4}$ \\ ${ }^{1}$ Key Laboratory of Cryogenics, Technical Institute of Physics and Chemistry, Chinese Academy of Sciences, \\ Beijing 100190, China \\ ${ }^{2}$ Division of Chemistry and Chemical Engineering, California Institute of Technology, 1200 E. California \\ Blvd. Pasadena, California 91125, USA \\ ${ }^{3}$ Materials Science, California Institute of Technology, 1200 California Blvd., Pasadena, California 91125, \\ USA \\ ${ }^{4}$ TMO University, Saint Petersburg 197101, Russia
}

(Received 16 November 2015; accepted 14 July 2016; published online 26 July 2016)

\begin{abstract}
Some group III elements such as Indium are known to produce the resonant impurity states in IV-VI compounds. The discovery of these impurity states has opened up new ways for engineering the thermoelectric properties of IV-VI compounds. In this work, resonant states in SnTe were studied by co-doping with both resonant (In) and extrinsic (Ag, I) dopants. A characteristic nonlinear relationship was observed between the Hall carrier concentration $\left(\mathrm{n}_{\mathrm{H}}\right)$ and extrinsic dopant concentration $\left(\mathrm{N}_{\mathrm{I}}, \mathrm{N}_{\mathrm{Ag}}\right)$ in the stabilization region, where a linear increase of dopant concentration does not lead to linear response in the measured $\mathrm{n}_{\mathrm{H}}$. Upon substituting extrinsic dopants beyond a certain amount, the $\mathrm{n}_{\mathrm{H}}$ changed proportionally with additional dopants (Ag, I) (the doping region). The Seebeck coefficients are enhanced as the resonant impurity is introduced, whereas the use of extrinsic doping only induces minor changes. Modest $z T$ enhancements are observed at lower temperatures, which lead to an increase in the average $z T$ values over a broad range of temperatures (300-773 K). The improved average $z T$ obtained through co-doping indicates the promise of fine carrier density control in maximizing the favorable effect of resonant levels for thermoelectric materials. Published by AIP Publishing. [http://dx.doi.org/10.1063/1.4959845]
\end{abstract}

Thermoelectric materials enable direct conversion between heat and electricity. The performance of thermoelectric materials can be evaluated with the dimensionless figure of merit, $z T=\sigma \alpha^{2} T / \kappa$, where $\sigma, \alpha, T$, and $\kappa$ are electrical conductivity, Seebeck coefficient, absolute temperature, and thermal conductivity, respectively. IV-VI compounds are known to have among the best thermoelectric properties of any material class. Especially at temperatures between $500 \mathrm{~K}$ and $900 \mathrm{~K}$, the lead chalcogenides and their alloys have been widely studied and generally show high $z T .^{1-6}$ Until recently, SnTe, a lead-free IV-VI narrow band-gap semiconductor, had not received as much attention as $\mathrm{PbTe}$ because of its relatively low $z T$. This low $z T$, found in intrinsic SnTe, is a result of its low Seebeck coefficient and high electronic thermal conductivity caused by an intrinsically high defect concentration $\left(p \sim 10^{20}-10^{21} \mathrm{~cm}^{-3}\right){ }^{6,7}$ The work by Zhou $\mathrm{et} \mathrm{al}$. shows that the valence band structure of SnTe is composed of both a very light, upper valence band and a heavier second valence band; of these, placing the Fermi level (electron chemical potential) nearer to the primary, light band edge yielded a better peak $z T$ of 0.6 at $700 \mathrm{~K}$ for $\mathrm{SnTe}_{0.985} \mathrm{I}_{0.015}$ (about 50\% higher than the $z T$ obtained for heavily doped $\mathrm{Gd}_{\mathrm{z}} \mathrm{Sn}_{1-\mathrm{z}} \mathrm{Te}$ and $\left.\mathrm{SnTe}_{1+\mathrm{y}}\right){ }^{8}$ Another strategy for improving $z T$ in SnTe was shown by Tan et al., who reported high $z T$ values of over 1.3 for $\mathrm{Cd}$ or $\mathrm{Hg}$ alloyed SnTe possibly due to band convergence of two valence bands and increased band gap..$^{9,10}$

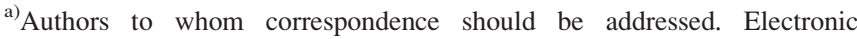
addresses: laifengli@mail.ipc.ac.cn and wangheng83@gmail.com
}

Indium has long been known to produce resonant levels in the valence band of SnTe as shown by Bushmarina and coworkers. ${ }^{11}$ It was proposed that these resonant levels stabilized the Fermi level position in the valence band and affect the thermoelectric properties. ${ }^{11}$ Recently, Zhang et al. demonstrated $z T$ of $1.1(873 \mathrm{~K})$ with In-doped $\mathrm{SnTe}$, which was attributed to the beneficial effect from the resonant levels and nanostructures. ${ }^{12}$ According to the current theory, ${ }^{13,14}$ the influence of resonant levels on the thermoelectric transport properties arises from two aspects: (1) A distortion of the density of states (DOS) of the host material that manifests itself as an increase of DOS near a characteristic energy level and (2) an additional scattering mechanism resulting from the resonating of carriers between conducting bands of the host material and localized impurity levels from the dopant. With the use of $\mathrm{Tl}$ as a resonant dopant in $\mathrm{PbTe}$, a high $z T$ of 1.5 was observed at $773 \mathrm{~K}$ for $\mathrm{Tl}_{0.02} \mathrm{~Pb}_{0.98} \mathrm{Te}^{15}$ Because intrinsic defect concentrations for most thermoelectric materials do not coincide with the optimum carrier density for $z T$, extrinsic doping is often necessary to achieve optimum performance. ${ }^{8,16-19}$ In the case of materials with resonant dopants, it is reasonable that adjusting the carrier concentration might also be a viable strategy for improving $z T$. Using additional extrinsic dopants (i.e., those without resonant levels) is necessary in order to independently adjust the carrier density for best thermoelectric performance. In this paper, we implement co-doping in In-doped SnTe using either acceptors (Ag) or donors (I) in an attempt to optimize the thermoelectric performance of co-doped $\operatorname{In}_{\mathrm{x}} \mathrm{Ag}_{\mathrm{z}} \mathrm{Sn}_{1-\mathrm{x}-\mathrm{z}} \mathrm{Te}$ and $\operatorname{In}_{\mathrm{x}} \mathrm{Sn}_{1-\mathrm{x}} \mathrm{Te}_{1-\mathrm{y}} \mathrm{I}_{\mathrm{y}}$ compounds. As a result, modest $z T$ enhancements are 
observed at low temperatures, which improve the average $z T$, indicating the promise of carrier density control in maximizing the favorable effect of resonant levels for thermoelectrics.

Polycrystalline samples of $\operatorname{In}_{\mathrm{x}} \mathrm{Sn}_{1-\mathrm{x}} \mathrm{Te}_{1-\mathrm{y}} \mathrm{I}_{\mathrm{y}}(0.0025 \leq x$ $\leq 0.01,0 \leq \mathrm{y} \leq 0.015)$ and $\mathrm{In}_{\mathrm{x}} \mathrm{Ag}_{\mathrm{z}} \mathrm{Sn}_{1-\mathrm{x}-\mathrm{z}} \mathrm{Te}(0.0025 \leq x$ $\leq 0.01,0 \leq \mathrm{y} \leq 0.015,0 \leq \mathrm{z} \leq 0.015$ ) (nominal compositions) were prepared by using a melt alloying and hot pressing technique. Pure elements (Sn, 99.999\%; Te, 99.999\%; In, 99.99\%; $\mathrm{Ag}, 99.999 \%)$ and ultra-dry $\mathrm{TeI}_{4}\left(\mathrm{TeI}_{4}, 99.999 \%\right)$ (total mass of about $10 \mathrm{~g}$ ) were weighed out according to each composition and loaded into quartz (fused silica) tubes, which were then evacuated and sealed. The sealed ampoules were slowly heated to $1273 \mathrm{~K}$ and kept for $24 \mathrm{~h}$ followed by water quenching. The ingots obtained were further annealed at $973 \mathrm{~K}$ for $120 \mathrm{~h}$ before being crushed and ground into fine powders. The powders were then hot pressed at $923 \mathrm{~K}$ under $1 \mathrm{~atm}$ argon with $40 \mathrm{MPa}$ pressure for $30 \mathrm{~min}$. A typical disk shaped sample obtained is $12 \mathrm{~mm}$ in diameter with density no less than $95 \%$ of theoretical density $\left(6.46 \mathrm{~g} / \mathrm{cm}^{3}\right)$. The phase composition was examined by X-ray diffraction (XRD) analysis with Bruker D8 Advance. The electrical resistivities and Hall coefficients $\left(R_{H}\right)$ were measured by using the Van der Pauw method in a magnetic field up to $\pm 2 \mathrm{~T}$. ${ }^{19}$ The Seebeck coefficients were obtained by measuring the thermoelectric voltages as well as temperatures with T-type thermocouples. ${ }^{20}$ The thermal conductivities were obtained by $\kappa=\mathrm{C}_{\mathrm{p}} \mathrm{D}_{\mathrm{T}} \mathrm{d}$ with the thermal diffusivity $D_{T}$ measured by the laser flash method (Netzsch LFA 457), where $d$ is the geometric density. The heat capacity $\mathrm{C}_{\mathrm{p}}$ was determined using the equation by $\mathrm{C}_{\mathrm{p}} / \mathrm{k}_{\mathrm{B}}$ per atom $=3.07+4.7 \times 10^{-4}(\mathrm{~T} / \mathrm{K}-300)$ by fitting experimental data as described in $\mathrm{PbTe}$ compound (where $k_{B}$ is Boltzmann's constant). ${ }^{21}$ The electronic thermal conductivity $\left(\kappa_{\mathrm{e}}\right)$ was calculated by using the equation $\kappa_{\mathrm{e}}=\mathrm{L} \sigma \mathrm{T}$, where $\sigma$ is the electrical conductivity, $\mathrm{T}$ is the absolute temperature, and $\mathrm{L}$ is the Lorenz number (In our previous paper, we show that due to the complex two-band nature of SnTe, it is difficult to obtain a satisfactory estimate of the Lorenz number; nonetheless, we will attempt to. To simplify the calculation, we use the Lorenz number of the un-doped SnTe estimated by using a single Kane Band (SKB) model over the whole temperature range ${ }^{8}$ ). The thermoelectric properties (the electrical resistivities, Seebeck coefficients, and the thermal diffusivities) were measured in the temperature range of 300-773 K. The $z T$ values were calculated by using the thermal conductivities, the electrical resistivities and Seebeck coefficients.

Figure 1 shows the composition dependences of the Hall carrier concentration and Seebeck coefficient for all codoped $\mathrm{In}_{\mathrm{x}} \mathrm{Sn}_{1-\mathrm{x}} \mathrm{Te}_{1-\mathrm{y}} \mathrm{I}_{\mathrm{y}}$ and $\mathrm{In}_{\mathrm{x}} \mathrm{Ag}_{\mathrm{z}} \mathrm{Sn}_{1-\mathrm{x}-\mathrm{z}} \mathrm{Te}$ compounds. The number density of I donor $\left(N_{I}\right)$ was plotted on the abscissa to the left, while that of $\mathrm{Ag}$ acceptor $\left(N_{A g}\right)$ to the right. From Figure 1(a), we see that the Hall carrier concentration $n_{H}$ of $\mathrm{In}_{0.01} \mathrm{Sn}_{0.99} \mathrm{Te}$ compound without $\mathrm{I} / \mathrm{Ag}$ dopants is $2.2 \times 10^{20} \mathrm{~cm}^{-3}$ at $300 \mathrm{~K}$. With additional $\mathrm{I}$ donor $\left(\mathrm{In}_{\mathrm{x}} \mathrm{Sn}_{1-\mathrm{x}} \mathrm{Te}_{1-\mathrm{y}} \mathrm{I}_{\mathrm{y}}\right)$ or $\mathrm{Ag}$ acceptor $\left(\mathrm{In}_{\mathrm{x}} \mathrm{Ag}_{\mathrm{z}} \mathrm{Sn}_{1-\mathrm{x}-\mathrm{z}} \mathrm{Te}\right)$ codoping, a relatively flat carrier concentration $\left(n_{H}\right)$ was observed until a certain amount of co-dopants was added, which we will call the stabilization region. The width of stabilization region for co-doped $\mathrm{In}_{0.01} \mathrm{Sn}_{0.99} \mathrm{Te}_{1-\mathrm{y}} \mathrm{I}_{\mathrm{y}}$ and $\mathrm{In}_{0.01} \mathrm{Ag}_{\mathrm{z}} \mathrm{Sn}_{0.99-\mathrm{z}} \mathrm{Te}$ is about $0.8 \times 10^{20} \mathrm{~cm}^{-3}$, as shown in Figure 1(a); however, the width (as determined by the number of resonant states) should be determined by the codoping efficiency, which is discussed later. In agreement with Bushmarina et al., this stabilization region width in Figure 1(a) is probably most representative of the $\mathrm{x}=0.01$ ( $1 \%$ indium) sample, while those with the lower indium contents have a smaller stabilization region width (the calculation of which was performed and is included in Table S1 in the supplementary material). ${ }^{25}$ Upon substituting additional dopants (I donors or Ag acceptors) beyond the stabilization region, the Hall carrier concentration changed proportionally with an additional impurity content $\left(N_{I}, N_{A g}\right)$ (called doping region). In the doping region (Figure $1(\mathrm{a})$ ), $\mathrm{Ag}$ substitutions appear to yield 2 holes per Ag atom (possibly a result of the production of additional cation vacancies). This is similar to the excess $\mathrm{Te}$ doped $\mathrm{In}_{0.01} \mathrm{Sn}_{0.99} \mathrm{Te}_{1+\omega}$ samples of Bushmarina et al. ${ }^{11}$ In that work, each extra Te atom was calculated to yield about 3 holes. The carrier concentration of I-doped $\mathrm{In}_{0.01} \mathrm{Sn}_{0.99} \mathrm{Te}_{1-\mathrm{y}} \mathrm{I}_{\mathrm{y}}$ in the doping region decreases with Iodine content, but at a slower rate $(\sim 70 \%$ dopant efficiency, consistent with previous work ${ }^{8}$ ). An analogous stabilization region and doping region were observed in In-doped SnTe with excess $\mathrm{Te} \mathrm{In}_{0.01} \mathrm{Sn}_{0.99} \mathrm{Te}_{1+\omega}$ alloys (open squares in Figure 1(a) $)^{11}$ and in Tl-doped PbTe compounds. ${ }^{22}$ From a simply chemistry point of view, in the presence of additional $\mathrm{Ag}$ acceptors, the valence of some Indium atoms change from $\mathrm{In}^{+}$to $\mathrm{In}^{3+}$ compensating the free hole generated by Ag. By contrast, $\mathrm{In}^{3+}$ changes to $\mathrm{In}^{+}$with additional Iodine donors in SnTe compound. That is, in the stabilization region the Indium impurity suppressed extrinsic doping and stabilized (pinned) the Fermi level. An analogous stabilization region and doping region are also observed for codoped compounds with different In contents $(x=0.005$ and 0.0025), as shown in Figure 1(a). Pinning of the Fermi level takes place by virtue of the high density of states (DOS) in the valence band as long as it is localized within the band of In impurity states (stabilization region). The Fermi level leaves the band when the additional dopants are high enough, resulting in a significant change of the Hall carrier concentration in the valence band in the doping region. In the stabilization region, Bushmarina et al. and other researchers ${ }^{11,22}$ suggested the additional dopants (Ag/I) should have no influence on the Hall carrier concentration, they instead alter the filling $\left(\mathrm{k}_{\mathrm{h}}\right)$ factor of the resonant states (for details see previous reviews on this topic ${ }^{13,22}$ ). Our experimental results qualitatively agree with this; however, scatter in the data and limited number of samples prevents us from drawing definitive conclusions.

The Seebeck coefficient in the co-doped $\operatorname{In}_{\mathrm{x}} \mathrm{Sn}_{1-\mathrm{x}} \mathrm{Te}_{1-\mathrm{y}} \mathrm{I}_{\mathrm{y}}$ and $\operatorname{In}_{\mathrm{x}} \mathrm{Ag}_{\mathrm{z}} \mathrm{Sn}_{1-\mathrm{x}-\mathrm{z}} \mathrm{Te}$ compounds is found to be related to the content of additional impurities $\left(N_{I}, N_{A g}\right)$ for the same Indium content. As shown in Figure 1(b), higher Seebeck coefficients are found within the stabilization region, whereas it decreases when carrier density is either below or above it. This is an indication of weakened influence from resonant levels as the Fermi level moves away. Arguably within the stabilization region the Seebeck coefficients are also different, with the minimum value found when additional dopants are absent and the maximum values when the dopant content is close to the boundary of this region. The reason for the maximum of Seebeck coefficient at the boundary of stabilization region 

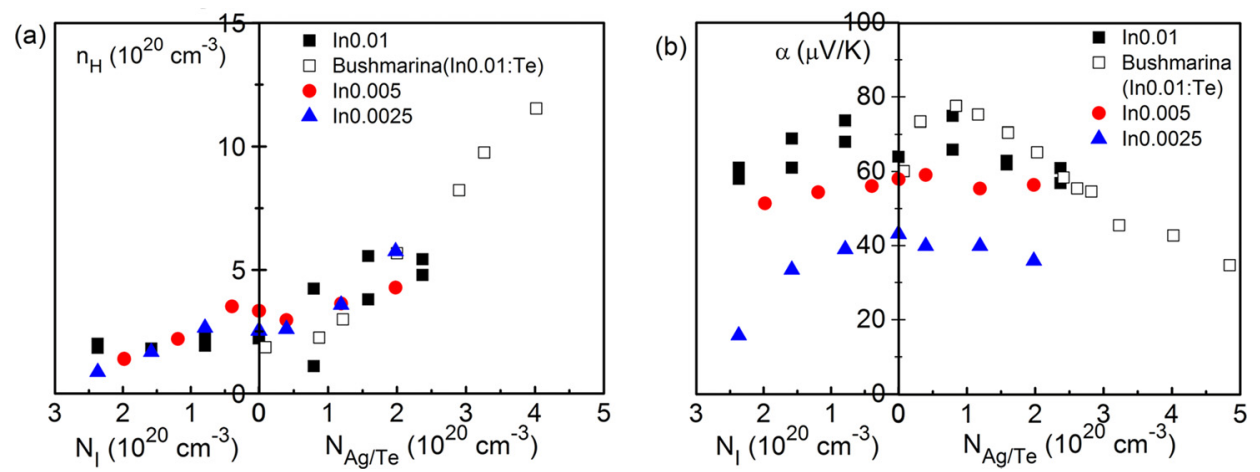

FIG. 1. (a) Hall carrier concentration, (b) Seebeck coefficient of co-doped $\operatorname{In}_{\mathrm{x}} \mathrm{Sn}_{1-\mathrm{x}} \mathrm{Te}_{1-\mathrm{y}} \mathrm{I}_{\mathrm{y}}$ and $\mathrm{In}_{\mathrm{x}} \mathrm{Ag}_{\mathrm{z}} \mathrm{Sn}_{1-\mathrm{x}-\mathrm{z}} \mathrm{Te}$ compounds at $300 \mathrm{~K}$. Solid squares are $1.0 \%$ In-doped SnTe, solid circles are 0.5\% In-doped SnTe, solid triangles are 0.25\% In-doped SnTe (two groups of co-doped $\mathrm{In}_{0.01} \mathrm{Sn}_{0.99} \mathrm{Te}_{1-\mathrm{y}} \mathrm{I}_{\mathrm{y}}$ and $\mathrm{In}_{0.01} \mathrm{Ag}_{\mathrm{z}} \mathrm{Sn}_{0.99-\mathrm{z}} \mathrm{Te}$ samples were fabricated and measured to confirm the results). The open squares data are from $\mathrm{In}_{0.01} \mathrm{Sn}_{0.99} \mathrm{Te}_{1+\omega}$ alloys with excess tellurium reported by Bushmarina ${ }^{11}$ (Reproduced with permission from Sov. Phys. Semicond.-USSR 18, 1374 (1984). Copyright American Institute of Physics). The carrier concentration of Ag-doped $\operatorname{In}_{0.01} \mathrm{Ag}_{\mathrm{z}} \mathrm{Sn}_{0.99-\mathrm{z}} \mathrm{Te}$ increases with $\mathrm{Ag}$ content in the doping region, $\mathrm{Ag}$ substitution appears to yield 2 holes per $\mathrm{Ag}$ atom ( 200\% doping efficiency), which possibly is a result of the production of additional cation vacancies. The carrier concentration of I-doped $\mathrm{In}_{0.01} \mathrm{Sn}_{0.99} \mathrm{Te}_{1-\mathrm{y}} \mathrm{I}_{\mathrm{y}}$ in the doping region decreases with Iodine content, but at a slower rate $(\sim 70 \% \text { doping efficiency, consistent with previous work })^{8}$ (Reproduced with permission from Zhou et al. Phys. Chem. Chem. Phys. 16, 20741 (2014). Copyright 2014 Royal Society of Chemistry).

and doping region is not clear yet. Bushmarina et al. attributed the maximum of Seebeck coefficient to the resonant scattering. ${ }^{11}$ However, the maximum of Seebeck coefficient should correspond to a minimum of carrier mobility in the case of the resonant scattering mechanism, which is in conflict with the experimental results for carrier mobility shown in Figure 2(b). Also, notice that Seebeck coefficients in samples with resonant levels are always higher than that without them given the same carrier density (as shown in Figure 2). This is consistent with the effect from a DOS distortion, whereas a fluctuation with both positive and negative influences on Seebeck coefficient is expected if the resonant scattering mechanism plays a dominant role, ${ }^{13}$ which is not supported by our experiment here. There is no available theory to quantitatively explain such Seebeck behavior observed, whereas there may be several mechanisms (DOS distortion, resonant scattering, nonresonant scattering by the $\mathrm{In}^{+}$and $\mathrm{In}^{3+}$ ions) that could account for it.

For the lower Indium contents ( $x=0.0025$ and 0.005$)$, the enhancement of Seebeck coefficient decreases as the number of available resonant levels decreases, which is consistent with either a DOS distortion or scattering mechanism. The change of Seebeck coefficients within the stabilization region is even less significant, possibly because (1) the region becomes narrower thus sampling point gets insufficient or (2) weakened influence from resonant levels in contrast with large "background" carrier population makes such change fall below uncertainty of these measurements.

The Seebeck coefficient as a function of Hall carrier concentration (Pisarenko plot) is shown in Figure 2(a) for all the co-doped $\operatorname{In}_{\mathrm{x}} \mathrm{Ag}_{\mathrm{z}} \mathrm{Sn}_{1-\mathrm{x}-\mathrm{z}} \mathrm{Te}$ and $\mathrm{In}_{\mathrm{x}} \mathrm{Sn}_{1-\mathrm{x}} \mathrm{Te}_{1-\mathrm{y}} \mathrm{I}_{\mathrm{y}}$ compounds $(\mathrm{x}=0.0025,0.005,0.01)$ along with our previous results of I-doped, Gd-doped SnTe, and reported results from Rogers and Zhang et al. ${ }^{8,12,23}$ The Seebeck coefficient for samples with no resonant dopant (I-, Gd-doped SnTe and Rogers reported results of $\mathrm{Bi}$ - and $\mathrm{Cu}$-doped $\mathrm{SnTe}$ ) with different carrier concentrations (from $2 \times 10^{19}$ to $2 \times 10^{21} \mathrm{~cm}^{-3}$ ) fit well to a two-valence-band model (solid line as shown in Figure 2(a)). Very low Seebeck coefficient values are observed for SnTe compounds due to the extremely light mass of the primary valence band and large offset to the heavier second band. ${ }^{8,23,24}$ Meanwhile, the samples containing resonant levels $\left(\mathrm{In}_{\mathrm{x}} \mathrm{Sn}_{1-\mathrm{x}} \mathrm{Te}_{1-\mathrm{y}} \mathrm{I}_{\mathrm{y}}\right.$ and $\mathrm{In}_{\mathrm{x}} \mathrm{Ag}_{\mathrm{z}} \mathrm{Sn}_{1-\mathrm{x}-\mathrm{z}} \mathrm{Te}$ ) generally have significantly higher Seebeck coefficient. Figure 2(b) shows the Hall mobility of all samples as a function of carrier density, where lower mobility in all Incontaining samples is found as a penalty of Seebeck coefficient enhancement. Different from the Seebeck coefficient, which shows a unique dependence on carrier density that is drastically different from the Pisarenko relation for regular semiconductors, the Hall mobility with resonant levels trend in a same way as those with regular dopants, only with consistently lower values. For the samples doped beyond the stabilization region, while the enhancements in their Seebeck coefficient are found to be weaker, the reduction in their mobility seems still significant, especially for those with lower carrier densities. We would like to note here that such a trend in mobility is surprising if the effect of resonant levels comes mainly from an additional scattering mechanism (resonant scattering, based on the current understanding), whereas an effect of DOS distortion might be consistent with our observation with certain assumptions.

Figure 3 shows the thermoelectric properties of the series of samples with the Indium content of $N_{I n}=1$ at. \% $\left(\operatorname{In}_{0.01}\right.$ $\mathrm{Sn}_{0.99} \mathrm{Te}_{1-\mathrm{y}} \mathrm{I}_{\mathrm{y}}$ and $\left.\mathrm{In}_{0.01} \mathrm{Ag}_{\mathrm{z}} \mathrm{Sn}_{0.99-\mathrm{z}} \mathrm{Te}\right)$. The thermoelectric properties of the other samples with lower Indium content $(x=0.005, x=0.0025)$ are shown in the supplementary material. ${ }^{25}$ The values of both electrical resistivity and Seebeck coefficient are consistent with the previous literature by Zhang et al. ${ }^{12}$ (open squares shown in Figures 3(a) and 3(b)). The temperature of resistivity increases from $0.5 \% \mathrm{I}$ to $1 \% \mathrm{I}$ as the carrier density decreases. It decreases again for $1.5 \% \mathrm{I}$ as carrier density is found higher in this sample, which is not expected. As shown in Figure 1(a), a relatively flat carrier concentration $\left(n_{H}\right)$ was observed in the stabilization region (corresponding to the co-doped $\operatorname{In}_{0.01} \mathrm{Sn}_{0.99} \mathrm{Te}_{0.995} \mathrm{I}_{0.005}$ and $\left.\mathrm{In}_{0.01} \mathrm{Ag}_{0.005} \mathrm{Sn}_{0.985} \mathrm{Te}\right)$. In the doping region ( $\mathrm{y}>0.005$ for $\mathrm{In}_{0.01} \mathrm{Sn}_{0.99} \mathrm{Te}_{1-\mathrm{y}} \mathrm{I}_{\mathrm{y}}$ and $\mathrm{z}>0.005$ for $\mathrm{In}_{0.01} \mathrm{Ag}_{\mathrm{z}} \mathrm{Sn}_{0.99-\mathrm{z}} \mathrm{Te}$ ), the Hall carrier concentration decreases with I-donors and increases with Ag-acceptors (as shown in Figure 1). However, the Hall carrier concentration of $\mathrm{In}_{0.01} \mathrm{Sn}_{0.99} \mathrm{Te}_{0.985} \mathrm{I}_{0.015}$ 
(a)

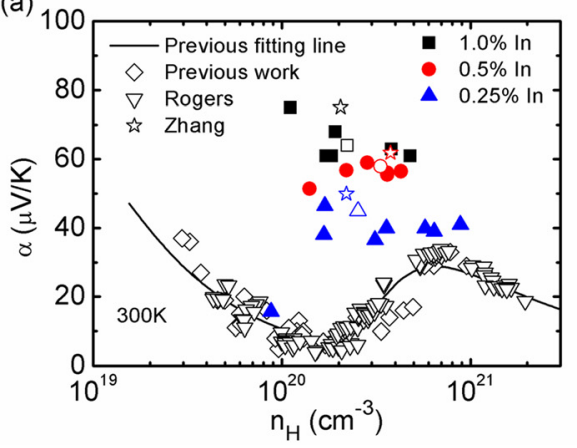

(b)

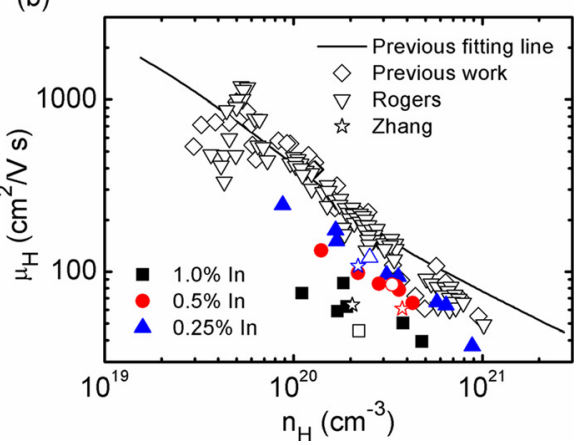

FIG. 2. (a) Seebeck coefficient and (b) Hall mobility as a function of Hall carrier concentration for co-doped $\operatorname{In}_{x} \operatorname{Sn}_{1-x} T_{1-y} I_{y}$ and $\operatorname{In}_{x} A g_{z} \operatorname{Sn}_{1-x-z} T e$ compounds. Solid marks are our experimental results of co-doped $\operatorname{In}_{x} \mathrm{Sn}_{1-\mathrm{x}} \mathrm{Te}_{1-\mathrm{y}} \mathrm{I}_{\mathrm{y}}$ and $\mathrm{In}_{\mathrm{x}} \mathrm{Ag}_{\mathrm{z}} \mathrm{Sn}_{1-\mathrm{x}-\mathrm{z}} \mathrm{Te}$ compounds (Solid squares are 1.0\% In-doped SnTe, solid circles are $0.5 \%$ In-doped SnTe, solid triangles are $0.25 \%$ In-doped SnTe). Open squares are Zhang's results of $\operatorname{In}_{x} \operatorname{Sn}_{1-\mathrm{x}} \mathrm{Te}(0.0025 \leq \mathrm{x} \leq 0.01)^{12}(\operatorname{Reproduced}$ with permission from Zhang et al., Proc. Natl. Acad. Sci. U.S.A. 110, 13261 (2013). Copyright 2013 National Academy of Sciences-Biactive work). Open triangles and open circles are Rogers' reported results and our previous result of Iodine- and Gd-doped SnTe results, respectively ${ }^{8,23}$ (Reproduced with permission from Zhou et al., Phys. Chem. Chem. Phys. 16, 20741 (2014). Copyright 2014 Royal Society of Chemistry. Reproduced with permission from L. M. Rogers, "Thermoelectric performance of co-doped SnTe with resonant levels," J. Phys. D: Appl. Phys. 1, 845 (1968). Copyright IOP Publishing). Solid curves are calculated from two band model as described in our previous paper $^{8}$ (Reproduced with permission from Zhou et al., Phys. Chem. Chem. Phys. 16, 20741 (2014). Copyright 2014 Royal Society of Chemistry).

$\left(1.84 \times 10^{20} \mathrm{~cm}^{-3}\right)$ is not lower but a little higher than that of $\operatorname{In}_{0.01} \mathrm{Sn}_{0.99} \mathrm{Te}_{0.99} \mathrm{I}_{0.01}\left(1.71 \times 10^{20} \mathrm{~cm}^{-3}\right)$, which could be due to (1) the low doping efficiency of Iodine in the $\operatorname{In}_{0.01}$ $\mathrm{Sn}_{0.99} \mathrm{Te}_{0.985} \mathrm{I}_{0.015}$, making the expected change less significant, and (2) variation among samples due to real synthesis conditions also adds uncertainty. On the other hand, additional $\mathrm{Ag}$ acceptors resulted in a decrease of electrical resistivity due to increased carrier concentration with $\mathrm{Ag}$ content in the doping region (shown in Figure 1).

The electrical resistivity and Seebeck coefficient of $\mathrm{In}_{0.01} \mathrm{Sn}_{0.99} \mathrm{Te}$ are $0.5 \mathrm{~m} \Omega \mathrm{cm}$ and $59 \mu \mathrm{V} / \mathrm{K}$ at room temperature and both increased with temperature (consistent with degenerate semiconducting behavior). The same behavior is also observed for all of the co-doped compounds. The Seebeck coefficient of In-doped $\operatorname{In}_{0.01} \mathrm{Sn}_{0.99} \mathrm{Te}$ is $65 \mu \mathrm{V} / \mathrm{K}$ at room temperature, which is $250 \%$ that of the un-doped $\mathrm{SnTe}_{1.005}$ with nearly the same carrier concentration $\left(n_{H}=2.2\right.$ $\times 10^{20} \mathrm{~cm}^{-3}$ for $\mathrm{In}_{0.01} \mathrm{Sn}_{0.99} \mathrm{Te}$ and $n_{H}=2 \times 10^{20} \mathrm{~cm}^{-3}$ for $\mathrm{SnTe}_{1.005}$ ). The enhancement of Seebeck coefficient (i.e., the percentage of increase over samples of same carrier density without resonant levels) decreases as temperature increases (as shown in Figure S4 in the supplementary material). ${ }^{25}$ It is not readily clear how the temperature might affect transport through either the resonant scattering mechanism or the DOS distortion; further, there is little known about how the position of resonant levels change with temperature. Nonetheless, the experimental result here indicates the effect of resonant levels gradually decreases regardless of doping level as temperature increases.

The thermal conductivity of the In-doped $\operatorname{In}_{0.01} \mathrm{Sn}_{0.99} \mathrm{Te}$ compound decreases with temperature and reaches $2 \mathrm{~W} / \mathrm{m} \mathrm{K}$ at $773 \mathrm{~K}$, consisting with the results of Zhang et al. ${ }^{12}$ (as shown by the open squares in Figure 3(c)). Thermal conductivities of SnTe with resonant levels are not significantly different from those doped with Iodine only from our previous study. ${ }^{8}$ Variation among samples can be explained by the difference in their electronic contribution (as shown in Figure S5 in the supplementary material), ${ }^{25}$ as well as influence from different amounts of dopant impurities.
The thermoelectric figure of merit, $z T$, is shown as a function of temperature in Figure 3(d) for all co-doped $\operatorname{In}_{0.01}$ $\mathrm{Sn}_{0.99} \mathrm{Te}_{1-\mathrm{y}} \mathrm{I}_{\mathrm{y}}$ and $\mathrm{In}_{0.01} \mathrm{Ag}_{\mathrm{z}} \mathrm{Sn}_{0.99-\mathrm{z}} \mathrm{Te}$ samples along with the results from Zhang et al. for In-doped $\mathrm{In}_{0.01} \mathrm{Sn}_{0.99} \mathrm{Te}$. ${ }^{12}$ The $z T$ value of $\operatorname{In}_{0.01} \operatorname{Sn}_{0.99} \mathrm{Te}\left(n_{H}=2.22 \times 10^{20} \mathrm{~cm}^{-3}\right)$ increases with temperature and yields a maximum of 0.63 at $773 \mathrm{~K}$, which is consistent with Zhang's result at the same temperature $\left(n_{H}\right.$ $\left.=2.1 \times 10^{20} \mathrm{~cm}^{-3}\right)($ as shown in Figure $3(\mathrm{~d}))$. The $z T$ enhancement upon co-doping with $\mathrm{Ag} / \mathrm{I}$ over that of the samples that only contain resonant dopant (In) is shown in Figure 3(e). The beneficial effect was observed to be strongest at low temperatures, but becomes less significant as temperatures increases. A large enhancement of $z T$ values at lower temperatures (even reaches to $180 \%$ enhancement at room temperature) contributes to higher average $z T$ values over a broad range of temperatures (as shown in Fig. 3(f)), indicating the promise of fine carrier density control in maximizing the favorable effect of resonant levels for thermoelectric materials.

To summarize, we have carried out a study of the thermoelectric performance for SnTe compounds through codoping of both resonant dopant (Indium) and additional dopants (Iodine donors and Ag acceptors). The Hall carrier concentration $\left(\mathrm{n}_{\mathrm{H}}\right)$ showed nonlinear behavior within a broad range of additional doping with $\mathrm{Ag}$ or I (the stabilization region). Upon substituting additional dopants (I donors or Ag acceptors) beyond a certain amount, the Hall carrier concentration changed proportionally with additional dopants (Ag, I) (the doping region). The Seebeck coefficient is enhanced regardless of additional doping ( $\mathrm{Ag}$ or I) but less so with excess amount of extrinsic doping at room temperature. Due to the fine tuning of electrical transport provided by additional dopants, peak $z T$ values of 0.63 were obtained at $773 \mathrm{~K}$ for some I-doped $\mathrm{In}_{0.01} \mathrm{Sn}_{0.99} \mathrm{Te}_{1-\mathrm{y}} \mathrm{I}_{\mathrm{y}}$ samples. An evident enhancement of zT values, especially at lower temperatures (even reaches to $180 \%$ enhancement at room temperature), is observed, which leads to an increase in the average $z T$ values over a broad range of temperatures (300-773 K). The improved average $z T$ obtained through codoping indicates the promise of fine carrier density control in 

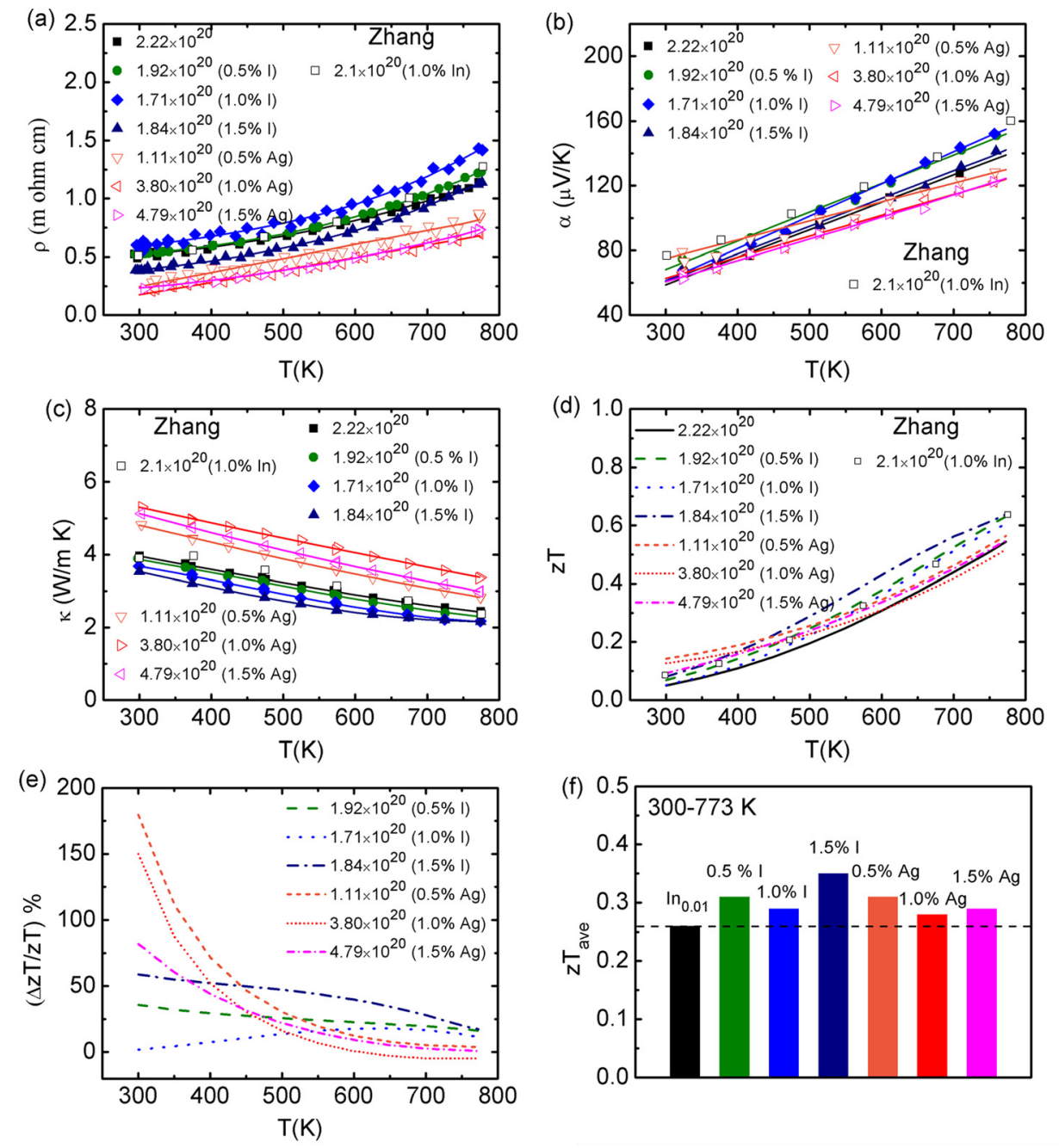

FIG. 3. Thermoelectric properties, (a) electrical resistivity, (b) Seebeck coefficient, (c) thermal conductivity, (d) $z T$ values, (e) the enhancement of $z T$ $((\Delta z T / z T) \%)$ values for co-doped $\operatorname{In}_{0.01}$ $\mathrm{Sn}_{0.99} \mathrm{Te}_{1-\mathrm{y}} \mathrm{I}_{\mathrm{y}}$ and $\mathrm{In}_{0.01} \mathrm{Ag}_{\mathrm{z}} \mathrm{Sn}_{0.99-\mathrm{z}} \mathrm{Te}$ alloys, and (f) the average zT values of co-doped $\mathrm{In}_{0.01} \mathrm{Sn}_{0.99} \mathrm{Te}_{1-\mathrm{y}} \mathrm{I}_{\mathrm{y}}$ and $\mathrm{In}_{0.01}$ $\mathrm{Ag}_{\mathrm{z}} \mathrm{Sn}_{0.99-\mathrm{z}} \mathrm{Te}$ alloys at temperature of $300-773 \mathrm{~K}$. The black open square data are from $\operatorname{In}_{0.01} \mathrm{Sn}_{0.99} \mathrm{Te}$ alloys reported by Zhang ${ }^{12}$ (Reproduced with permission from Zhang et al., Proc. Natl. Acad. Sci. U.S.A. 110, 13261 (2013). Copyright 2013 National Academy of Sciences-Biactive work). The legends in the above figures represent the co-doped $\operatorname{In}_{0.01} \mathrm{Sn}_{0.99} \mathrm{Te}_{1-\mathrm{y}} \mathrm{I}_{\mathrm{y}}$ or $\mathrm{In}_{0.01} \mathrm{Ag}_{\mathrm{z}} \mathrm{Sn}_{0.99-\mathrm{z}} \mathrm{Te}$ alloys with different $\mathrm{I} / \mathrm{Ag}$ content. (For example, " $0.5 \%$ I-doped" represents the $\mathrm{In}_{0.01}$ $\mathrm{Sn}_{0.99} \mathrm{Te}_{0.995} \mathrm{I}_{0.005}$ sample, the corresponding Hall carrier concentration at room temperature was show in Table S2 in the supplementary material. ${ }^{25}$ ) In (e), " $\Delta z T$ " equals to the $z T$ values of $\mathrm{In}_{0.01} \mathrm{Sn}_{0.99} \mathrm{Te}_{1-\mathrm{y}} \mathrm{I}_{\mathrm{y}} / \mathrm{In}_{0.01} \mathrm{Ag}_{\mathrm{z}} \mathrm{Sn}_{0.99-\mathrm{z}} \mathrm{Te}$ minus the $z T$ values of $\operatorname{In}_{0.01} \mathrm{Sn}_{0.99} \mathrm{Te}$, " $z T$ " refers to the $z T$ values of $\mathrm{In}_{0.01} \mathrm{Sn}_{0.99} \mathrm{Te}$. maximizing the favorable effect of resonant levels for thermoelectric materials.

${ }^{1}$ M. G. Kanatzidis, Chem. Mater. 22, 648-659 (2010).

${ }^{2}$ S. N. Girard, J. Q. He, X. Y. Zhou, D. Shoemaker, C. M. Jaworski, C. Uher, V. P. Dravid, J. P. Heremans, and M. G. Kanatzidis, J. Am. Chem. Soc. 133, 16588-16597 (2011).

${ }^{3}$ Y. Pei, J. Lensch-Falk, E. S. Toberer, D. L. Medlin, and G. J. Snyder, Adv. Funct. Mater. 21, 241-249 (2011).

${ }^{4}$ K. Ahn, M.-K. Han, J. He, J. Androulakis, S. Ballikaya, C. Uher, V. P. Dravid, and M. G. Kanatzidis, J. Am. Chem. Soc. 132, 5227-5235 (2010).

${ }^{5}$ Y. Pei, N. A. Heinz, A. LaLonde, and G. J. Snyder, Energy Environ. Sci. 4, 3640-3645 (2011).

${ }^{6}$ R. F. Brebrick and A. J. Strauss, Phys. Rev. 131, 104 (1963).

${ }^{7}$ V. P. Vedeneev, S. P. Krivoruchko, and E. P. Sabo, Semiconductors 32 , 241-244 (1998).

${ }^{8}$ M. Zhou, Z. M. Gibbs, H. Wang, Y. Han, C. Xin, L. Li, and G. J. Snyder, Phys. Chem. Chem. Phys. 16, 20741-20748 (2014).

${ }^{9}$ G. Tan, L.-D. Zhao, F. Shi, J. W. Doak, S.-H. Lo, H. Sun, C. Wolverton, V. P. Dravid, C. Uher, and M. G. Kanatzidis, J. Am. Chem. Soc. 136, 7006-7017 (2014).

${ }^{10}$ G. Tan, F. Shi, J. W. Doak, H. Sun, L.-D. Zhao, P. Wang, C. Uher, C. Wolverton, V. P. Dravid, and M. G. Kanatzidis, Energy Environ. Sci. 8, 267-277 (2015).

${ }^{11}$ G. S. Bushmarina, B. F. Gruzinov, I. A. Drabkin, E. Y. Lev, and V. M. Yuneev, Sov. Phys. Semicond.-USSR 18, 1374-1377 (1984).

${ }^{12}$ Q. Zhang, B. Liao, Y. Lan, K. Lukas, W. Liu, K. Esfarjani, C. Opeil, D. Broido, G. Chen, and Z. Ren, Proc. Natl. Acad. Sci. U.S.A. 110, 13261-13266 (2013).

${ }^{13}$ V. I. Kaidanov and Yu. I. Ravich, Sov. Phys. Usp. 28(1), 31-53 (1985).
${ }^{14}$ J. P. Heremans, B. Wiendlocha, and A. M. Chamoire, "Resonant levels in bulk thermoelectric semiconductors," Energy Environ. Sci. 5(2), 5510-5530 (2012).

${ }^{15}$ J. P. Heremans, V. Jovovic, E. S. Toberer, A. Saramat, K. Kurosaki, A. Charoenphakdee, S. Yamanaka, and G. J. Snyder, Science 321, 554-557 (2008).

${ }^{16}$ A. D. LaLonde, Y. Pei, and G. J. Snyder, Energy Environ. Sci. 4, 2090-2096 (2011).

${ }^{17}$ Y. Pei, Z. M. Gibbs, A. Gloskovskii, B. Balke, W. G. Zeier, and G. J. Snyder, Adv. Energy Mater. 4(13), 1400486 (2014).

${ }^{18}$ H. Wang, Z. M. Gibbs, Y. Takagiwac, and G. J. Snyder, Energy Environ. Sci. 7, 804-811 (2014).

${ }^{19}$ K. A. Borup, E. S. Toberer, L. D. Zoltan, G. Nakatsukasa, M. Errico, J.-P. Fleurial, B. B. Iversen, and G. J. Snyder, Rev. Sci. Instrum. 83, 123902 (2012).

${ }^{20}$ S. Iwanaga, E. S. Toberer, A. LaLonde, and G. J. Snyder, Rev. Sci. Instrum. 82, 063905 (2011).

${ }^{21}$ R. Blachnik and R. Igel, Z. Naturforsch., B-J. Chem. Sci. B 29(9-10), 625-629 (1974).

${ }^{22}$ S. A. Nemov and Y. I. Ravich, Usp. Fiz. Nauk 168, 817-842 (1998).

${ }^{23}$ L. M. Rogers, J. Phys. D: Appl. Phys. 1, 845-852 (1968).

${ }^{24}$ R. F. Brebrick, J. Phys. Chem. Solids 24, 27-36 (1963).

${ }^{25}$ See supplementary material at http://dx.doi.org/10.1063/1.4959845 for the thermoelectric properties of co-doped $\operatorname{In}_{\mathrm{x}} \mathrm{Sn}_{1-\mathrm{x}} \mathrm{Te}_{1-\mathrm{y}} \mathrm{I}_{\mathrm{y}}$ and $\mathrm{In}_{\mathrm{x}} \mathrm{Ag}_{\mathrm{z}} \mathrm{Sn}_{1-\mathrm{x}-\mathrm{z}} \mathrm{Te}$ alloys $(x=0.0025,0.005)$, the $\mathrm{X}$-ray diffraction patterns and the electronic thermal conductivity of co-doped $\mathrm{In}_{0.01} \mathrm{Sn}_{0.99} \mathrm{Te}_{0.99} \mathrm{I}_{\mathrm{y}}$ and $\mathrm{In}_{0.01} \mathrm{Ag}_{\mathrm{z}} \mathrm{Sn}_{0.99-\mathrm{z}} \mathrm{Te}$ alloys, the Seebeck coefficient enhancement $(\Delta \alpha / \alpha)$ of the In-doped $\mathrm{In}_{0.01} \mathrm{Sn}_{0.99} \mathrm{Te}$ compared to that of the un-doped $\mathrm{SnTe}_{1.005}$ without resonant levels, the stabilization region width of the co-doped $\operatorname{In}_{\mathrm{x}} \mathrm{Sn}_{1-\mathrm{x}} \mathrm{Te}_{1-\mathrm{y}} \mathrm{I}_{\mathrm{y}}$ and $\mathrm{In}_{\mathrm{x}} \mathrm{Ag}_{\mathrm{z}} \mathrm{Sn}_{1-\mathrm{x}-\mathrm{z}} \mathrm{Te}$ compounds with different Indium content $(\mathrm{x}=0.0025$, $0.005,0.01)$. 